\title{
Oligogalacturonides: plant damage-associated molecular patterns and regulators of growth and development
}

\author{
Simone Ferrari, Daniel V. Savatin, Francesca Sicilia, Giovanna Gramegna, Felice Cervone and \\ Giulia De Lorenzo*
}

Dipartimento di Biologia e Biotecnologie "Charles Darwin", Sapienza Università di Roma, Rome, Italy

\section{Edited by:}

Sjef Smeekens, Utrecht University, Netherlands

\section{Reviewed by:}

Henrik Scheller, Lawrence Berkeley National Laboratory, USA lan Wallace, The University of California at Berkeley, USA

\section{${ }^{*}$ Correspondence:}

Giulia De Lorenzo, Dipartimento di Biologia e Biotecnologie "Charles Darwin," Sapienza Università di Roma, Piazzale Aldo Moro 5, 00185 Rome, Italy.

e-mail: giulia.delorenzo@uniroma1.it
Oligogalacturonides (OGs) are oligomers of alpha-1,4-linked galacturonosyl residues released from plant cell walls upon partial degradation of homogalacturonan. OGs are able to elicit defense responses, including accumulation of reactive oxygen species and pathogenesis-related proteins, and protect plants against pathogen infections. Recent studies demonstrated that OGs are perceived by wall-associated kinases and share signaling components with microbe-associated molecular patterns. For this reason OGs are now considered true damage-associated molecular patterns that activate the plant innate immunity and may also be involved in the activation of responses to mechanical wounding. Furthermore, OGs appear to modulate developmental processes, likely through their ability to antagonize auxin responses. Here we review our current knowledge on the role and mode of action of this class of oligosaccharides in plant defense and development.

Keywords: oligogalacturonides, damage-associated molecular patterns, innate immunity, pectin, elicitors, signal transduction, defense responses, cell wall

\section{INTRODUCTION}

The first evidence that pectin fragments induce defense responses was provided more than 30 years ago by assaying phytoalexin accumulation in soybean cotyledons (Hahn et al., 1981). These fragments, called endogenous elicitors, were later identified as oligomers of alpha-1,4-linked galacturonosyl residues (oligogalacturonides, OGs) that can be obtained by partial hydrolysis of polygalacturonic acid (Nothnagel et al., 1983). It was speculated that the degradation of a major component of pectin, i.e., homogalacturonan (HGA), which occurs during microbial infections, may cause the accumulation of OGs that trigger defense responses. Around that time, it was shown that digestion of HGA by a fungal or a tomato-derived polygalacturonase (PG) releases an elicitor of a wound-inducible proteinase inhibitor (PI), suggesting a role of OGs in the wound response (Bishop et al., 1981). A few years later it was reported that OGs antagonize the activity of auxin during pea stem elongation, envisioning a possible role of these oligosaccharides as regulators of growth and development (Branca et al., 1988). In subsequent years, efforts were made to elucidate the mechanism of action of OGs and to investigate their ability to trigger plant defenses as well as to affect, as local antagonists of auxin, plant growth and development. However, only recently significant progress has been made in understanding the basis of OG perception and signal transduction. Here we review our current knowledge on the effects and mode of action of OGs in plant defense and development.

\section{OGs ARE ELICITORS OF DEFENSE RESPONSES}

Pathogens need to be recognized in a timely manner by the host in order to activate the proper defenses that restrict invasion and colonization. A crucial feature of the innate immune system in both plants and animals is the ability to sense a potential danger through the recognition of molecules that alert the cell. Molecules associated with pathogenic microbes (microbe-associated molecular patterns, MAMPs), like chitin from fungi, peptidoglycan and flagellin from bacteria and glucans from the cell wall of oomycetes are specifically sensed by the host cells and trigger an immune response (Bittel and Robatzek, 2007; Boller and Felix, 2009). MAMP-triggered immunity is now a fertile field of research in plant biology.

Response to endogenous signals originating from stressed or injured cells, the so-called "regulation from within," is now emerging as an important function of the immune system. Endogenous molecules with elicitor activity are released from cellular components during pathogen attack or abiotic stresses, and have been indicated as damage-associated molecular patterns (DAMPs) in both plants (Boller and Felix, 2009; Galletti et al., 2009; Tor et al., 2009; De Lorenzo et al., 2011; Ranf et al., 2011) and animals, where they have also been called alarmins (Bianchi, 2007; Lotze et al., 2007). OGs are probably the best characterized plant DAMPs and elicit in several plant species a wide range of defense responses, including accumulation of phytoalexins (Davis et al., 1986), glucanase, and chitinase (Davis and Hahlbrock, 1987; Broekaert and Pneumas, 1988), deposition of callose, production of reactive oxygen species (ROS; Bellincampi et al., 2000; Galletti et al., 2008), and nitric oxide (Rasul et al., 2012; Figure 1). OGs are thought to be released from plant cell walls upon partial degradation of HGA by microbial PGs during infections (Cervone et al., 1989) or by the action of endogenous PGs induced by mechanical damage (Orozco-Cardenas and Ryan, 1999). The signaling activity of OGs is a clear indication that plants have evolved mechanisms to monitor HGA degradation for the early detection of tissue injury. Pectin is one of the most accessible components of the cell and, therefore, is among the first structures to be altered during an attempted 


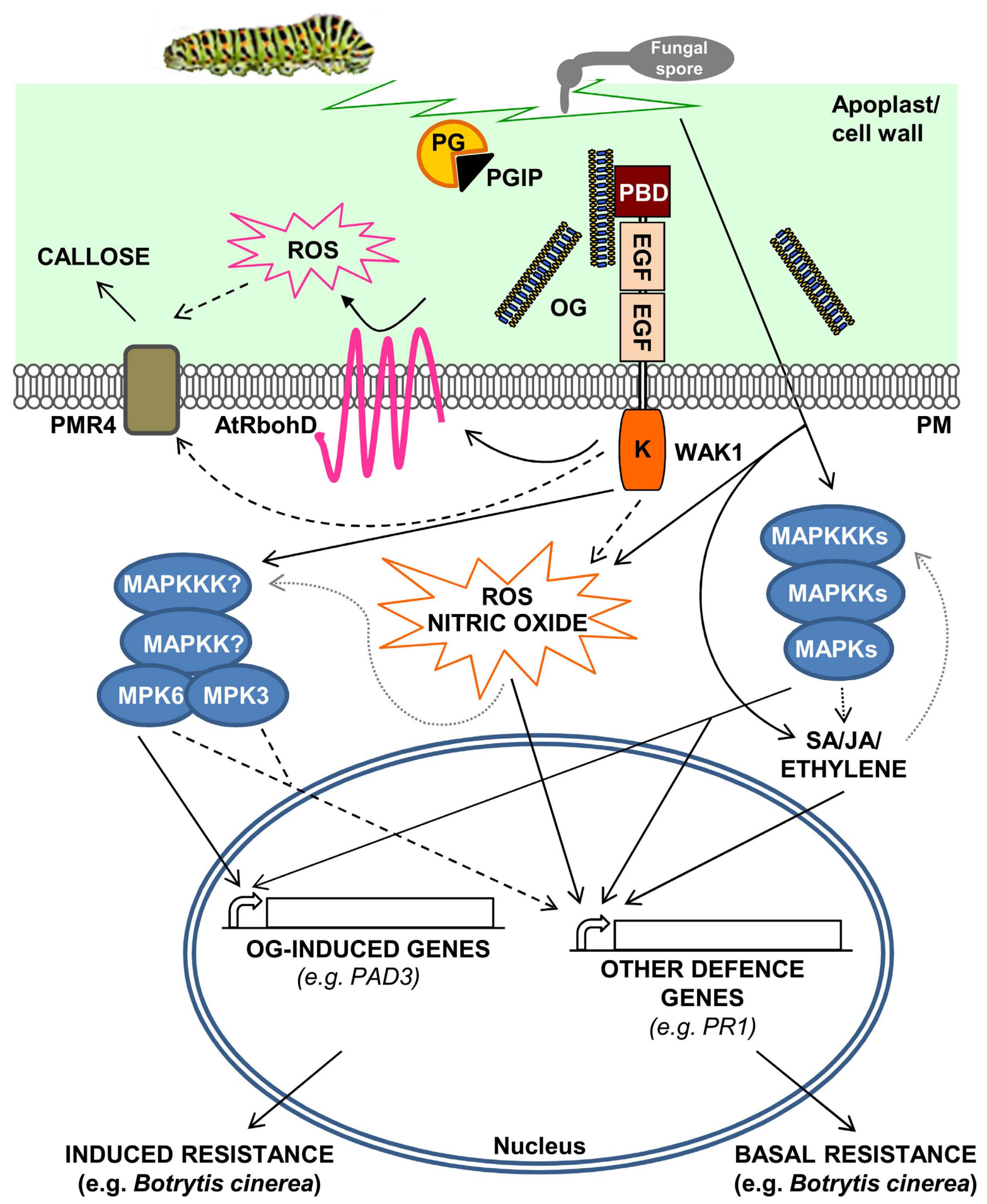

FIGURE 1 | A model for the activation of Arabidopsis thaliana defense responses triggered by oligogalacturonides (OGs). OGs are released from the cell wall after degradation of homogalacturonan by mechanical damage or by the action of hydrolytic enzymes such as PGs, secreted by pathogens. PGIPs in the apoplast modulate PG activity, favoring the accumulation of elicitor-active OGs, which function as DAMPs. OGs are perceived by WAK 1 and trigger defense responses such as ROS accumulation through the activation of the NADPH oxidase AtRbohD, nitric oxide production, callose deposition, and MAPK-mediated activation of defense gene expression. Pathogen invasion or mechanical damage also cause an increase of JA, SA, and ethylene levels, mediated by MAPK cascades, triggering defense responses independently of OGs. DAMP- and hormone-mediated defense responses result, respectively, in induced and basal resistance toward necrotrophic pathogens, such as Botrytis cinerea. Dashed lines indicate hypothetical cascades; dotted gray lines indicate oversimplification of the complex and still partially uncharacterized roles of MAPKs in the regulation of hormone and ROS synthesis/response. 
pathogen invasion or when the wall undergoes a stress rupture (De Lorenzo and Ferrari, 2002). Since plant cell wall integrity may be efficiently watched by monitoring the pectin status, we have proposed the existence of a system, called "pectin integrity monitoring system" or PIMS, dedicated to this function (De Lorenzo et al., 2011). OGs are likely located in a key position in PIMS, that allows them to act as indicators of cell wall integrity, both in adverse conditions and during normal growth (see below). Moreover, because HGA-degrading enzymes such as PGs are among the first enzymes secreted by microbes during host colonization, PIMS also includes the inhibitors of fungal and insect PGs (PGinhibiting proteins or PGIPs), which guard the cell wall by limiting HGA degradation (De Lorenzo et al., 2001; De Lorenzo and Ferrari, 2002; Di Matteo et al., 2006). By inhibiting the action of PGs secreted by pathogens, PGIPs not only hinder pectin degradation, but also favor the accumulation of elicitor-active OGs (De Lorenzo et al., 1994, 2001; De Lorenzo and Ferrari, 2002), thus playing a dual role in PIMS.

A structural requirement for the biological activity of OGs is a degree of polymerization (DP) between 10 and 15 (Côté and Hahn, 1994). This size is optimal for the formation of $\mathrm{Ca}^{2+}$. mediated intermolecular cross-links resulting in structures called "egg boxes" (Braccini and Perez, 2001; Cabrera et al., 2008), that are thought to be necessary for OG activity. Modification of the reducing end of OGs does not affect the formation of egg boxes (Cabrera et al., 2008) and does not affect elicitor activity (unpublished results of our lab). OGs with a DP of 2-6, which we indicate as short OGs, have been reported in a few cases to exhibit elicitor activity as, for instance, during the induced expression of PIs in tomato (Farmer and Ryan, 1990; Moloshok et al., 1992); however, short OGs appear to suppress defense responses in wheat (Moerschbacher et al., 1999). HGA is synthesized in an esterified form in the Golgi apparatus and, subsequently, is secreted into the cell wall where it undergoes a partial de-esterification by the action of pectin methylesterases (PMEs; Pelloux et al., 2007). The degree of esterification of HGA varies in different tissues according to the specific developmental stage (Wolf et al., 2009); consequently OGs with different degrees of esterification are expected to be released under diverse circumstances. In most studies, OGs have been prepared from polygalacturonic acid digested with commercial PGs (Nothnagel et al., 1983; Galletti et al., 2008; Cabrera et al., 2010), and it is not yet clear how esterification affects their biological activity. Acetylated OGs, but not de-esterified OGs, reduce the haustoria formation of Blumeria graminis growing on wheat leaves, suggesting that esterification is necessary for some specific responses (Pelloux et al., 2007; Randoux et al., 2010). The presence of OGs with a low degree of methylation in strawberry fruits overexpressing a PME was correlated with the expression of defense responses and with a concomitant partial resistance against Botrytis cinerea (Osorio et al., 2008). On the other hand, Arabidopsis thaliana plants overexpressing an inhibitor of PME or mutated in an endogenous PME have a high degree of pectin methylesterification (Lionetti et al., 2007, 2010; Raiola et al., 2010, 2011). These plants do not show constitutive expression of defense responses but, nevertheless, exhibit enhanced resistance to Botrytis cinerea and Pectobacterium carotovorum. A reduced growth of these pathogens on highly methylated pectin as a carbon source may in part explain the resistant phenotype of these plants (Lionetti et al., 2012).

\section{DISSECTION OF OG SIGNALING}

Until recently, the effects of OGs were studied in non-model plants, such as soybean (Hahn et al., 1981), and therefore it was difficult to identify the molecular components responsible for their perception and transduction. An additional limitation of these studies was that OG production and accumulation is hard to detect in vivo, unless in the presence of a massive tissue degradation that generally occurs only during the later stages of plant infections (An et al., 2005). The adoption of Arabidopsis as a model plant has provided a useful tool to advance our knowledge of the OG biology. Notably, the responses triggered by OGs in Arabidopsis largely overlap those activated by MAMPs. For instance, transcript profiling of seedlings treated with either OGs or flg22, i.e., a peptide that comprises the active epitope of flagellin (GomezGomez et al., 1999), indicates an extensive overlap of responses, at least at the early times after treatment (30-60 min; Denoux et al., 2008). In Arabidopsis, both elicitors activate a set of responses that are independent of the signaling pathways involving ethylene, salicylic acid (SA), and jasmonate (JA; Zipfel et al., 2004; Ferrari et al., 2007) and induce the phosphorylation of two mitogen-activated protein kinases (MAPKs), namely AtMPK3 and AtMPK6 (Denoux et al., 2008; Galletti et al., 2011). AtMPK6 appears necessary for the early expression of defense genes and for the induced resistance against Botrytis cinerea triggered by these elicitors (Galletti et al., 2011). Furthermore, both OGs and flg22 trigger a robust oxidative burst mediated by the nicotinamide adenine dinucleotide phosphate (NADPH) oxidase AtRbohD, which is at least partially responsible for the subsequent production of callose (Zhang et al., 2007; Galletti et al., 2008) by the callose synthase POWDERY MILDEW RESISTANT 4 (Nishimura et al., 2003; Figure 1). However, OGs are relatively weak elicitors compared to flg22, probably as a consequence of their reduced half-life (Denoux et al., 2008). For instance, flg22 and other MAMPs, in contrast to OGs, induce the expression of defense genes dependent on SA, JA, and ethylene signaling, such as the well characterized SA-dependent marker gene PR-1 (Denoux et al., 2008). These additional defense responses likely contribute to basal resistance to pathogens. Moreover, OGs are endogenous signals likely released in low amounts also in healthy plant tissues, as a consequence of developmentally related cell wall remodeling processes. Whether plants can discriminate between low physiological doses and higher amounts of OGs produced in pathological situations has not been elucidated yet. Intriguingly, a mutual interference has been observed between responses induced by flg22 and OGs, suggesting that they differ not only from a quantitative, but also from a qualitative point of view (Aslam et al., 2009).

Understanding how OGs are perceived is necessary to elucidate their role in vivo, but the identification of an OG receptor has been daunting for a long time. Wall-associated kinases (WAKs) were indicated as interesting candidates because of their ability to bind OGs and polygalacturonic acid (Anderson et al., 2001; Decreux and Messiaen, 2005). WAKs are receptor-like kinases, with an extracellular domain containing epidermal growth factor motifs, a transmembrane domain and an intracellular Ser/Thr kinase 
domain (Anderson et al., 2001). Arabidopsis has a small family of five WAK genes and a larger family of 22 WAK-like (WAKLs) genes (Verica et al., 2003), though in monocots these families appear largely expanded (Zhang et al., 2005). WAKs were first identified in Arabidopsis as pectin-bound proteins, since only harsh treatments, i.e., boiling in the presence of high concentrations of detergents and reducing agents or pectinase digestion could solubilize a protein reacting with an anti-WAK polyclonal antibody (He et al., 1996; Lally et al., 2001; Wagner and Kohorn, 2001). The same band of about $68 \mathrm{kDa}$ (lower than the theoretical $78 \mathrm{kDa}$ mass of the mature WAK1, which contains eight predicted glycosylation sites), also reacted with monoclonal antibodies against partially esterified HGA (Wagner and Kohorn, 2001). This led to the conclusion that WAK1 is tightly bound to pectin. Subsequently, WAK1 was shown to carry a N-terminal pectin binding domain that interacts with non-methylesterified HGA and OGs in a $\mathrm{Ca}^{2+}$-dependent manner (Decreux and Messiaen, 2005). Notably, OGs with DP $>9$ (i.e., those with elicitor activity) bind reversibly to WAK1 and binding increases when OGs are present as dimers in a calciummediated "egg box" conformation (Cabrera et al., 2008). Decreux et al. (2006), using site-directed mutagenesis, also identified five basic amino acids in the WAK1 ectodomain that are involved in the binding to HGA dimers and multimers. The ectodomains of WAK1 and WAK2 bind de-esterified HGA but not highly esterified HGA or other structurally different pectic components, such as rhamnogalacturonan I (RGI) and rhamnogalacturonan II (RGII; Kohorn et al., 2009). This behavior is at odds with the observation that leaf mesophyll protoplasts from a wak 2 knock out (KO) mutant are unable to induce the expression of a vacuolar invertase gene upon treatment with either de-esterified and esterified HGA, RGI, and RGII (Kohorn et al., 2009). Whether wak2 protoplasts have reduced responsiveness specifically to pectin and not to other non-pectic polysaccharide signals, such as chitin or chitosan, was not verified. These data are difficult to be taken as an evidence that WAK2 is a receptor for pectin: given the size and the extreme structural complexity of pectin, proposing its interaction with WAKs as a classical receptor-ligand interaction without pointing to a specific structural domain as a target for recognition, can be misleading (Kohorn and Kohorn, 2012). Many observations, instead, indicate a specificity or at least a preference of WAK1 and WAK2 for de-esterified HGA and for OGs (Decreux and Messiaen, 2005; Kohorn et al., 2009). The hypothesis of WAKs as receptors of OGs has been difficult to test through conventional genetic approaches due to functional redundancy. In particular, Arabidopsis KO mutants for individual WAK genes do not show a significant altered OG responsiveness (unpublished results), and generation of double or multiple mutants is difficult because the genes are tightly clustered (Verica et al., 2003). A chimeric receptor approach, however, revealed that WAK1 acts as a receptor of OGs (Brutus et al., 2010). The extracellular domain of WAK1 was fused with the kinase portion of EF-Tu receptor (EFR), the receptor of the bacterial MAMP elf18 (Zipfel et al., 2006), and the chimeric receptor was able to activate the kinase domain in response to OGs. On the other hand, upon stimulation with elf18, a chimeric receptor formed by the EFR ectodomain and the kinase domain of WAK1 activated the typical responses triggered by OGs.
Both pectin and OGs affect plant gene expression, but the induced transcriptional profiles appear different. For instance, the expression of about 50 genes is up-regulated in Arabidopsis protoplasts treated with high molecular weight pectin (Kohorn et al., 2009), whereas the expression of more than one thousand genes is induced in Arabidopsis seedlings treated with OGs (Ferrari et al., 2007; Denoux etal., 2008). Notably, very few of the genes up-regulated by pectin treatments are also induced by OGs in seedlings. Probably, pectin and OGs trigger different responses, and more than one receptor is involved in their perception.

The analysis of the expression of WAKs and WAKLs suggests that most of them play a role in defense. Public microarray data indicate that WAK1, WAK2, and WAK3 are all induced by Phytophthora parasitica, ozone and benzothiadiazole, an activator of the systemic acquired resistance, while WAK1 and WAK2 are also induced by SA. Interestingly, WAK1 is induced in Arabidopsis seedlings by OGs, but, unexpectedly, none of the WAKs is upregulated by flg22 (Denoux et al., 2008). Overexpression of WAK1 in Arabidopsis or of the rice OsWAK1 increases resistance to Botrytis cinerea and Magnaporthe oryzae, respectively (Li et al., 2009; Brutus et al., 2010); the Arabidopsis WAKL22 confers resistance to Fusarium oxysporum (Diener and Ausubel, 2005), though its mode of action is not known.

The role of WAKs under physiological conditions is less clear. Since pectin is tightly linked to the extracellular domain of WAKs, these proteins are good candidates to monitor pectin integrity. Indeed, reduced expression of WAKs through inducible antisense constructs causes reduced growth, suggesting a role of these proteins in regulating cell expansion (Lally et al., 2001; Wagner and Kohorn, 2001). This is in agreement with the observation that wak2 mutants have reduced growth only in the absence of osmotic support, suggesting that they have a defect in cell wall structure and/or composition (Kohorn et al., 2006).

The perception of non-self molecules or of a damaged self is a taxonomically widespread mechanism, and may have an adaptive significance. Striking parallels exist between pectin/OGs and hyaluronan/hyaluronan fragments found in animal cells. The breakdown of hyaluronan, a component of the animal extracellular matrix, upon tissue injury or pathogen infection, activates the vertebrate innate immune system (Jiang et al., 2011). Hyaluronan fragments are sensed by the plasma membrane leucine-rich repeat receptors Toll-like receptor 2 (TLR2) and TLR4 (Taylor et al., 2007), which are also required for the perception and activation of the immune response by MAMPs (Scheibner et al., 2006). It is therefore clear that both plants and animals have evolved analogous systems to activate the innate immunity in response to both MAMPs and DAMPs.

\section{OGs ACT AS SIGNALS IN THE WOUND RESPONSE}

Recognition of OGs is likely a crucial function of the plant PIMS, under both physiological and pathological circumstances. One of the most common dangers faced by plants is wounding, as the injured tissue represents an easy entry point for pathogen colonization. Plants are able to sense mechanically damaged tissues as an altered self and respond by activating localized defenses similar to those activated by pathogen infection. These include a rapid oxidative burst (Bradley et al., 1992; Brisson et al., 1994), the 
expression of defense-related genes (Reymond et al., 2000) and the accumulation of pathogenesis-related proteins (Chang et al., 1995; Figure 1). Several genes affected by wounding are also regulated in response to pathogens (Reymond and Farmer, 1998; Durrant et al., 2000; Reymond et al., 2000). A study on the local and systemic wound-induced accumulation of PIs in tomato led to the discovery of systemin, a peptide signal that specifically mediates the systemic wound response, and revealed that also OGs are able to induce PI accumulation (Ryan and Jagendorf, 1995). Therefore, OGs have been hypothesized to be involved in wound signaling, because they can be generated both directly by the physical disruption of HGA and by the action of endogenous PGs (Figure 1). Indeed, a tomato PG has been described to be responsible for the production of OGs after wounding (Bergey et al., 1999). However, OGs are likely to act only as local signals, because of their oligoanionic nature and limited mobility in the tissues (Baydoun and Fry, 1985). Their action is independent of systemin: transgenic plants expressing an antisense transcript that decreases systemin levels are defective in the systemic but not in the local expression of PI in response to wounding and normally respond to OGs (McGurl et al., 1992).

Jasmonate is an essential signal in the tomato systemic wound response (Sun et al., 2011), albeit full activation of several JAregulated defense responses requires ethylene (O'Donnell et al., 1996; Ryan and Moura, 2002). The observations that several wound-responsive genes are JA-independent and that local and systemic wound-induced gene expression are different suggested the existence of two separate signaling pathways in tomato: one mediated by systemin and JA and responsible for the systemic response, the other mediated by OGs but not by JA, and functioning only locally. Cross-talk between the two pathways has been proposed, since OG-induced production of ROS in tomato cells is potentiated by systemin (Stennis et al., 1998). In Arabidopsis, like in tomato, both JA and ethylene are required for a stronger and more rapid expression of several wound-responsive genes (Moffat et al., 2012), and local and systemic responses to wounding are different (Rojo et al., 1999, 2003; Delessert et al., 2004). Moreover, also in Arabidopsis, OGs up-regulate several woundresponsive genes independently of JA (Leon et al., 2001). However, there are important differences between the wound responses of tomato and Arabidopsis. For example, genes encoding systemin are absent in Arabidopsis, and JA synthesis is induced by OGs and chitosan in tomato, whereas JA does not accumulate in Arabidopsis plants treated with chitosan. In Arabidopsis, chitosan blocks JA-induced gene expression through an ethylene-dependent pathway (Rojo etal., 1999). At present, there is no evidence that OGs induce ethylene synthesis (Ferrari et al., 2008; Brutus et al., 2010) and it is not known whether they block JA-induced responses.

Oligogalacturonides protect Arabidopsis and grapevine against Botrytis cinerea (Aziz et al., 2004; Ferrari et al., 2007). Notably, wounding of Arabidopsis induces a strong resistance against the same pathogen (Chassot et al., 2008). Local resistance induced by both OGs and wounding is independent of SA-, JA-, and ethylenemediated signaling pathways and requires PHYTOALEXIN DEFICIENT 3 (PAD3; Ferrari etal., 2007; Chassot et al., 2008), a cytochrome P450 that catalyses the last step of camalexin biosynthesis (Zhou et al., 1999). Camalexin accumulation is not observed after wounding (Chassot et al., 2008) nor after OG treatment (Ferrari, unpublished results), although priming of camalexin accumulation after inoculation with Botrytis cinerea has been observed in wounded leaves (Chassot et al., 2008). These data suggest that wound-induced resistance to Botrytis cinerea is mediated by OGs. However, systemic protection against Botrytis cinerea is not observed after wounding (Chassot et al., 2008), whereas syringe-infiltration with OGs increases both local and systemic resistance to the fungus (Ferrari et al., 2007), possibly because the amount of infiltrated OGs is higher than that released in the tissue during mechanical damage. It must be also noted that both wounding (Cheong et al., 2002) and OGs (Branca et al., 1988; Bellincampi et al., 1996; Ferrari et al., 2008; Savatin et al., 2011) repress auxin responses (see below), supporting the hypothesis that OGs mediate at least some responses induced by mechanical damage.

\section{ARE OGs REGULATORS OF PLANT GROWTH AND DEVELOPMENT?}

Dynamic interactions between plant cells depending on the status of pectin in the cell wall are emerging as important regulatory mechanisms of growth and development (Wolf et al., 2012). Because pectin is among the first components that are modified when the wall undergoes physiological remodeling, OGs may be important not only in defense against pathogens, but also under physiological conditions. Over time, OGs have been reported to have effects on plant growth and development. One of the first described effects, i.e., the induction of tomato fruit ripening through the induction of ethylene, was later shown to be mediated by OGs in the size range of DP 4-6 and not 10-15 (Simpson et al., 1998).

Auxins, and in particular indole-3-acetic acid (IAA), are crucial for plant growth and development (Leyser, 2002). Physiological responses to auxins can be antagonized by OGs, as described for the first time by Branca etal. (1988), who showed that auxin-induced elongation in pea stem segments is competitively inhibited by OGs. OGs have been subsequently shown to inhibit auxin-induced root formation in tobacco and Arabidopsis leaf explants as well as in thin cell-layer explants (Bellincampi et al., 1993; Savatin et al., 2011) and to induce flower formation in explants that do not normally form organs (Marfà et al., 1991). Moreover, OGs inhibit the stimulation by auxin of the mitotic activity that leads to stomata formation and enhance mean wall thickness of foliar pericycle cells, mainly through cellulose deposition, as well as the number of extra-thick-walled pericycle cells (Altamura et al., 1998). At the molecular level, OGs interfere with the activation of promoters up-regulated by auxin, such as those of the tobacco gene Nt114 and of the Agrobacterium rhizogenes rolB expressed in tobacco (Bellincampi et al., 1996; Mauro et al., 2002). Although OGs do not simply act by inhibiting the action of IAA (Spiro et al., 2002), most of the developmental effects of OGs may be explained with their ability to antagonize auxin responses.

In Arabidopsis, the transcription of several auxin-induced genes (e.g., IAA5, SAUR16, and SAUR-AC1), as well as the activation of the synthetic auxin-responsive promoter DR5 (Ulmasov et al., 1997) are inhibited by OGs independently of 
SA, JA, and ethylene and of AtrbohD-mediated $\mathrm{H}_{2} \mathrm{O}_{2}$ accumulation (Savatin et al., 2011). Different elements of the auxin signaling pathway were analyzed as potential targets for OGmediated inhibition. Auxin acts by binding the F-box protein TRANSPORT INHIBITOR RESPONSE 1 (TIR1) and its homologs AUXIN SIGNALLING F-BOXES (AFBs) and promoting the degradation of the AUXIN/INDOLE-3-ACETIC ACID (Aux/IAA) transcriptional repressors (Gray et al., 2001; Dharmasiri etal., 2005). It was reported that the bacterial elicitor flagellin represses auxin responses in Arabidopsis through the induction of a microRNA(miR393) directed against TIR1/AFB transcripts (Navarro et al., 2006); this induction, however, occurs only at high doses of the elicitor (Savatin etal., 2011). The antagonism between OGs and auxin does not involve the silencing of TIR1/AFB genes, nor requires miR393 activity or posttranscriptional gene silencing (Savatin etal., 2011). Moreover, OG-auxin antagonism also occurs when the auxin-regulated genes are induced by the translation inhibitor cycloheximide, suggesting that OGs may act downstream of Aux/IAA repressors, possibly at the level of the promoter regions of auxin-responsive genes (Figure 2).

\section{CONCLUSION}

Oligogalacturonides are very well characterized elicitors of plant defense and are capable of protecting plants against diseases. Their involvement in the local wound response is another interesting

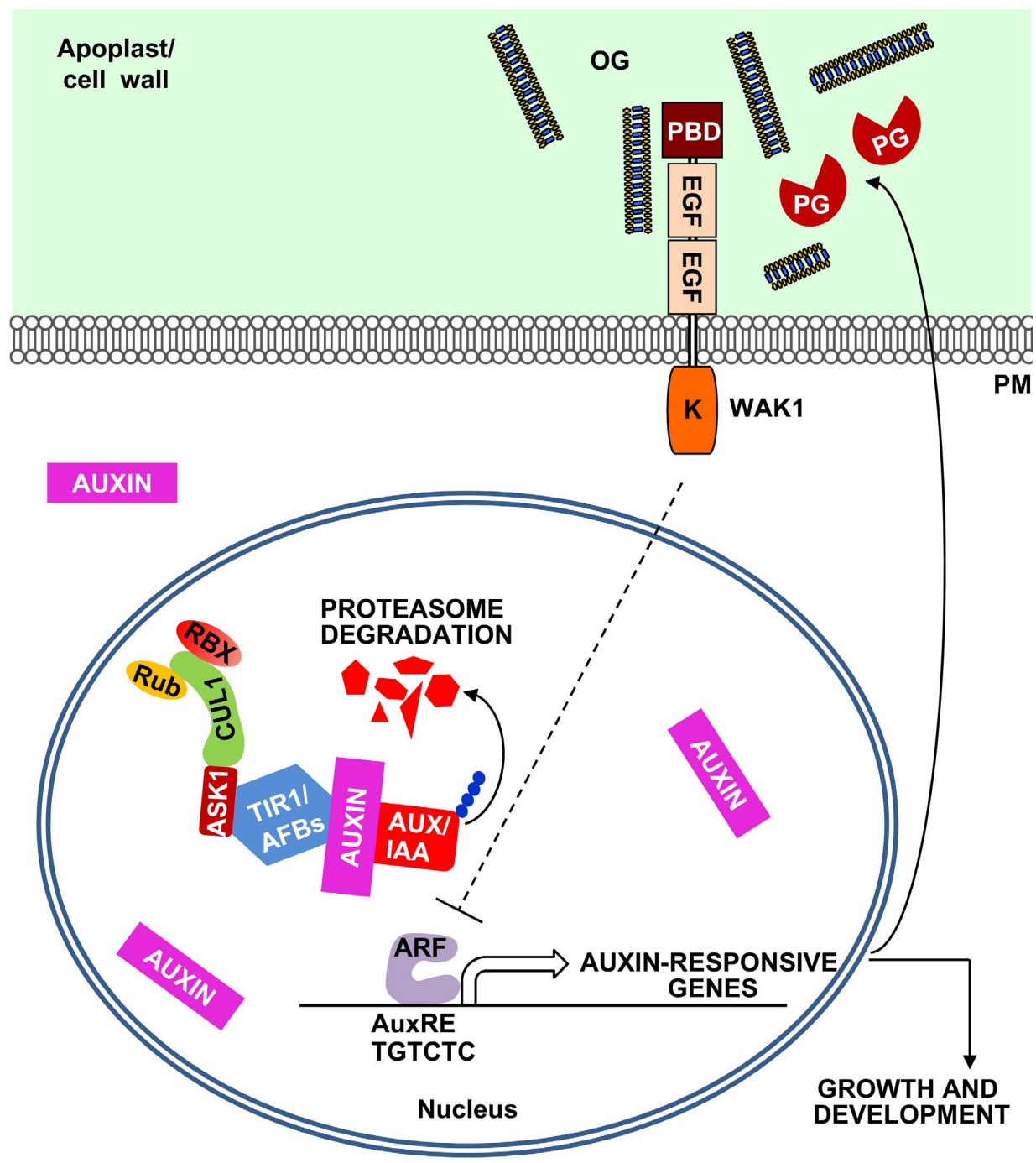

FIGURE 2 | A model for the OG-mediated negative feedback regulation of the auxin responses. Plant cells sense auxin through the receptors TIR1/AFBs, F-box proteins that form a SCF E3 ubiquitin ligase complex together with SKP (ASK1) and CULLIN1 (CUL1). This complex is regulated by RUB1 conjugating enzyme (Rub) and RING BOX1 (RBX) proteins and, in the presence of auxin, leads to the ubiquitination of Aux/IAA repressors and their proteasome-mediated degradation. Aux/IAA degradation releases auxin response factors (ARFs) that initiate the transcription of auxin-responsive genes, characterized by the presence of auxin response elements (AuxREs) in their promoters. Auxin also induces the expression of plant PGs and other pectin-degrading enzymes (Laskowski et al., 2006). The action of these enzymes may release in the apoplast OGs that can inhibit auxin-related responses, establishing a negative feedback loop 
feature of OGs. Possibly, these elicitors have a general function of "priming" plant defenses upon cell wall damage that occurs at the early stages of a microbial invasion or during insect attack. OGs may also work as regulators of plant growth and development mainly through their antagonism with auxin. Cell division and elongation are often orchestrated by auxin and require cell wall modifications. It is relevant that auxin induces the expression of PGs and other pectin-degrading enzymes (Laskowski et al., 2006). These enzymes, in turn, may release OGs in the apoplast for a negative feedback regulation of the auxin action. To date, there is no evidence for inhibition of plant PGs by PGIPs; however, the few plant PGs so far characterized have a specific activity much lower than that of the pathogen-secreted enzymes. Thus, the release of OGs during growth and development may not require modulation by PGIPs. The role of OGs as regulators of growth

\section{REFERENCES}

Altamura, M. M., Zaghi, D., Salvi, G., De Lorenzo, G., and Bellincampi, D. (1998). Oligogalacturonides stimulate pericycle cell wall thickening and cell divisions leading to stoma formation in tobacco leaf explants. Planta 204, 429-436.

An, H. J., Lurie, S., Greve, L. C., Rosenquist, D., Kirmiz, C., Labavitch, J. M., et al. (2005). Determination of pathogen-related enzyme action by mass spectrometry analysis of pectin breakdown products of plant cell walls. Anal. Biochem. 338, 71-82.

Anderson, C. M., Wagner, T. A., Perret, M., He, Z. H., He, D., and Kohorn, B. D. (2001). WAKs: cell wall-associated kinases linking the cytoplasm to the extracellular matrix. Plant Mol. Biol. 47, 197-206.

Aslam, S. N., Erbs, G., Morrissey, K. L., Newman, M. A., Chinchilla, D., Boller, T., et al. (2009). Microbe-associated molecular pattern (MAMP) signatures, synergy, size and charge: influences on perception or mobility and host defence responses. Mol. Plant Pathol. 10, 375-387.

Aziz, A., Heyraud, A., and Lambert, B. (2004). Oligogalacturonide signal transduction, induction of defenserelated responses and protection of grapevine against Botrytis cinerea. Planta 218, 767-774.

Baydoun, E. A. H., and Fry, S. C. (1985). The immobility of pectic substances in injured tomato leaves and its bearing on the identity of the wound hormone. Planta 165, 269-276.

Bellincampi, D., Cardarelli, M., Zaghi, D., Serino, G., Salvi, G., Gatz, C., et al. (1996). Oligogalacturonides prevent rhizogenesis in rolB transformed tobacco explants by inhibiting auxin-induced expression of the rolB gene. Plant Cell 8, 477-487.
Bellincampi, D., Dipierro, N., Salvi, G., Cervone, F., and De Lorenzo, G. (2000). Extracellular $\mathrm{H}_{2} \mathrm{O}_{2}$ induced by oligogalacturonides is not involved in the inhibition of the auxinregulated rolB gene expression in tobacco leaf explants. Plant Physiol. 122, 1379-1385.

Bellincampi, D., Salvi, G., De Lorenzo, G., Cervone, F., Marfa, V., Eberhard, S., et al. (1993). Oligogalacturonides inhibit the formation of roots on tobacco explants. Plant J. 4, 207-213.

Bergey, D. R., Orozco-Cardenas, M., De Moura, D. S., and Ryan, C. A. (1999). A wound- and systemin-inducible polygalacturonase in tomato leaves. Proc. Natl. Acad. Sci. U.S.A. 96, 1756-1760.

Bianchi, M. E. (2007). DAMPs, PAMPs and alarmins: all we need to know about danger. J. Leukoc. Biol. 81, 1-5.

Bishop, P. D., Makus, D. J., Pearce, G., and Ryan, C. A. (1981). Proteinase inhibitor-inducing factor activity in tomato leaves resides in oligosaccharides enzymically released from cell walls. Proc. Natl. Acad. Sci. U.S.A. 78, 3536-3540.

Bittel, P., and Robatzek, S. (2007). Microbe-associated molecular patterns (MAMPs) probe plant immunity. Curr. Opin. Plant Biol. 10, 335-341.

Boller, T., and Felix, G. (2009). A renaissance of elicitors: perception of microbe-associated molecular patterns and danger signals by patternrecognition receptors. Annu. Rev. Plant Biol. 60, 379-406.

Braccini, I., and Perez, S. (2001). Molecular basis of $\mathrm{Ca}(2+)$-induced gelation in alginates and pectins: the egg-box model revisited. Biomacromolecules 2, 1089-1096.

Bradley, D. J., Kjellbom, P., and Lamb, C. J. (1992). Elicitor- and woundinduced oxidative cross-linking of a proline-rich plant cell wall protein: a

and development is still an interesting speculation, based so far on experiments involving their exogenous applications. Whether OGs accumulate to a significant concentration in intact tissues that are not affected by a microbial infection and whether they act as endogenous regulators of physiological processes is still to be proven.

\section{ACKNOWLEDGMENTS}

This work was supported by the ERC (ERC_AdG_233083 grant awarded to Felice Cervone), by the Ministero dell'Istruzione, dell'Università e della Ricerca (PRIN2009 WTCJL8 and FIRB ERAPG RBER063SN4 grants awarded to Giulia De Lorenzo), by the Istituto Pasteur - Fondazione Cenci-Bolognetti and by Sapienza Università di Roma (Ricerche Universitarie C26A10ME4X grant awarded to Giulia De Lorenzo).

novel, rapid defense response. Cell 70, 21-30.

Branca, C., De Lorenzo, G., and Cervone, F. (1988). Competitive inhibition of the auxin-induced elongation by $\alpha$-D-oligogalacturonides in pea stem segments. Physiol. Plant. 72 , 499-504.

Brisson, L. F., Tenhaken, R., and Lamb, C. (1994). Function of oxidative cross-linking of cell wall structural proteins in plant disease resistance. Plant Cell 6, 1703-1712.

Broekaert, W. F., and Pneumas, W. J. (1988). Pectic polysaccharides elicit chitinase accumulation in tobacco. Physiol. Plant. 74, 740-744.

Brutus, A., Sicilia, F., Macone, A., Cervone, F., and De Lorenzo, G. (2010). A domain swap approach reveals a role of the plant wall-associated kinase 1 (WAK1) as a receptor of oligogalacturonides. Proc. Natl. Acad. Sci. U.S.A. 107, 9452-9457.

Cabrera, J. C., Boland, A., Cambier, P., Frettinger, P., and Van Cutsem, P. (2010). Chitosan oligosaccharides modulate the supramolecular conformation and the biological activity of oligogalacturonides in Arabidopsis. Glycobiology 20, 775-786.

Cabrera, J. C., Boland, A., Messiaen, J., Cambier, P., and Van Cutsem, P. (2008). Egg box conformation of oligogalacturonides: the time-dependent stabilization of the elicitor-active conformation increases its biological activity. Glycobiology 18, 473-482.

Cervone, F., Hahn, M. G., De Lorenzo, G., Darvill, A., and Albersheim, P. (1989). Host-pathogen interactions. XXXIII. A plant protein converts a fungal pathogenesis factor into an elicitor of plant defense responses. Plant Physiol. 90, 542-548.

Chang, M.-M., Horovitz, D., Culley, D., and Hadwiger, L. A. (1995). Molecular cloning and characterization of a pea chitinase gene expressed in response to wounding, fungal infection and the elicitor chitosan. Plant Mol. Biol. 28, 105-111.

Chassot, C., Buchala, A., Schoonbeek, H. J., Metraux, J. P., and Lamotte, O. (2008). Wounding of Arabidopsis leaves causes a powerful but transient protection against Botrytis infection. Plant J. 55, 555-567.

Cheong, Y. H., Chang, H. S., Gupta, R., Wang, X., Zhu, T., and Luan, S. (2002). Transcriptional profiling reveals novel interactions between wounding, pathogen, abiotic stress, and hormonal responses in Arabidopsis. Plant Physiol. 129, 661-677.

Côté, F., and Hahn, M. G. (1994). Oligosaccharins: structures and signal transduction. Plant Mol. Biol. 26, 1379-1411.

Davis, K. R., Darvill, A. G., Albersheim, P., and Dell, A. (1986). Host-pathogen interactions. XXIX. Oligogalacturonides released from sodium polypectate by endopolygalacturonic acid lyase are elicitors of phytoalexins in soybean. Plant Physiol. 80, 568-577.

Davis, K. R., and Hahlbrock, K. (1987). Induction of defense responses in cultured parsley cells by plant cell wall fragments. Plant Physiol. 85, 1286-1290.

De Lorenzo, G., Brutus, A., Savatin, D. V., Sicilia, F., and Cervone, F. (2011). Engineering plant resistance by constructing chimeric receptors that recognize damage-associated molecular patterns (DAMPs). FEBS Lett. 585, 1521-1528.

De Lorenzo, G., Cervone, F., Bellincampi, D., Caprari, C., Clark, A. J., Desiderio, A., et al. (1994). Polygalacturonase, PGIP and oligogalacturonides in cell-cell communication. Biochem. Soc. Trans. 22, 396-399. 
De Lorenzo, G., D’Ovidio, R., and Cervone, F. (2001). The role of polygacturonase-inhibiting proteins (PGIPs) in defense against pathogenic fungi. Annu. Rev. Phytopathol. 39, 313-335.

De Lorenzo, G., and Ferrari, S. (2002). Polygalacturonase-inhibiting proteins in defense against phytopathogenic fungi. Curr. Opin. Plant Biol. 5, 295-299.

Decreux, A., and Messiaen, J. (2005). Wall-associated kinase WAK1 interacts with cell wall pectins in a calcium-induced conformation. Plant Cell Physiol. 46, 268-278.

Decreux, A., Thomas, A., Spies, B., Brasseur, R., Van Cutsem, P., and Messiaen, J. (2006). In vitro characterization of the homogalacturonan-binding domain of the wall-associated kinase WAK1 using site-directed mutagenesis. Phytochemistry 67, 1068-1079.

Delessert, C., Wilson, I. W., Van Der, S. D., Dennis, E. S., and Dolferus, R. (2004). Spatial and temporal analysis of the local response to wounding in Arabidopsis leaves. Plant Mol. Biol. 55, 165-181.

Denoux, C., Galletti, R., Mammarella, N., Gopalan, S., Werck, D., De Lorenzo, G., et al. (2008). Activation of defense response pathways by OGs and Flg22 elicitors in Arabidopsis seedlings. Mol. Plant 1, 423-445.

Dharmasiri, N., Dharmasiri, S., and Estelle, M. (2005). The F-box protein TIR 1 is an auxin receptor. Nature 435, 441-445.

Diener, A. C., and Ausubel, F. M. (2005). Resistance to Fusarium oxysporum 1, a dominant Arabidopsis diseaseresistance gene, is not race specific. Genetics 171, 305-321.

Di Matteo, A., Bonivento, D., Tsernoglou, D., Federici, L., and Cervone, F. (2006). Polygalacturonaseinhibiting protein (PGIP) in plant defence: a structural view. Phytochemistry 67, 528-533.

Durrant, W. E., Rowland, O., Piedras, P., Hammond-Kosack, K. E., and Jones, J. D. (2000). cDNA-AFLP reveals a striking overlap in race-specific resistance and wound response gene expression profiles. Plant Cell 12, 963-977.

Farmer, E. E., and Ryan, C. A. (1990). Interplant communication: airborne methyl jasmonate induces expression of protease inhibitor genes in plant leaves. Proc. Natl. Acad. Sci. U.S.A. 87, 7713-7716.

Ferrari, S., Galletti, R., Denoux, C., De Lorenzo, G., Ausubel, F. M., and Dewdney, J. (2007). Resistance to
Botrytis cinerea induced in Arabidopsis by elicitors is independent of salicylic acid, ethylene, or jasmonate signaling but requires PHYTOALEXIN DEFICIENT3. Plant Physiol. 144, 367-379.

Ferrari, S., Galletti, R., Pontiggia, D., Manfredini, C., Lionetti, V., Bellincampi, D., et al. (2008). Transgenic expression of a fungal endo-polygalacturonase increases plant resistance to pathogens and reduces auxin sensitivity. Plant Physiol. 146, 669-681.

Galletti, R., De Lorenzo, G., and Ferrari, S. (2009). Host-derived signals activate plant innate immunity. Plant Signal. Behav. 4, 33-34.

Galletti, R., Denoux, C., Gambetta, S., Dewdney, J., Ausubel, F. M., De Lorenzo, G., et al. (2008). The AtrbohD-mediated oxidative burst elicited by oligogalacturonides in Arabidopsis is dispensable for the activation of defense responses effective against Botrytis cinerea. Plant Physiol. 148, 1695-1706.

Galletti, R., Ferrari, S., and De Lorenzo, G. (2011). Arabidopsis MPK3 and MPK6 play different roles in basal and oligogalacturonide- or flagellin-induced resistance against Botrytis cinerea. Plant Physiol. 157, 804-814.

Gomez-Gomez, L., Felix, G., and Boller, T. (1999). A single locus determines sensitivity to bacterial flagellin in Arabidopsis thaliana. Plant J. 18, 277-284.

Gray, W. M., Kepinski, S., Rouse, D., Leyser, O., and Estelle, M (2001). Auxin regulates SCF(TIR1)dependent degradation of AUX/IAA proteins. Nature 414, 271-276.

Hahn, M. G., Darvill, A. G., and Albersheim, P. (1981). Host-pathogen interactions. XIX. The endogenous elicitor, a fragment of a plant cell wall polysaccharide that elicits phytoalexin accumulation in soybeans. Plant Physiol. 68, 11611169.

He, Z. H., Fujiki, M., and Kohorn, B. D. (1996). A cell wall-associated, receptor-like protein kinase. J. Biol. Chem. 271, 19789-19793.

Jiang, D., Liang, J., and Noble, P. W. (2011). Hyaluronan as an immune regulator in human diseases. Physiol. Rev. 91, 221-264.

Kohorn, B. D., Johansen, S., Shishido, A., Todorova, T., Martinez, R., Defeo, E., et al. (2009). Pectin activation of MAP kinase and gene expression is WAK2 dependent. Plant J. 60, 974-982.

Kohorn, B. D., Kobayashi, M., Johansen, S., Riese, J., Huang, L. F., Koch, K., et al. (2006). An Arabidopsis cell wallassociated kinase required for invertase activity and cell growth. Plant $J$ 46, 307-316

Kohorn, B. D., and Kohorn, S. L. (2012). The cell wall-associated kinases, WAKs, as pectin receptors. Front. Plant Sci. 3:88. doi: 10.3389/fpls.2012.00088

Lally, D., Ingmire, P., Tong, H. Y., and He, Z. H. (2001). Antisense expression of a cell wall-associated protein kinase, WAK4, inhibits cell elongation and alters morphology. Plant Cell 13, 1317-1331.

Laskowski, M., Biller, S., Stanley, K., Kajstura, T., and Prusty, R. (2006). Expression profiling of auxin-treated Arabidopsis roots: toward a molecular analysis of lateral root emergence. Plant Cell Physiol. 47, 788-792.

Leon, J., Rojo, E., and Sanchez-Serrano, J. J. (2001). Wound signalling in plants. J. Exp. Bot. 52, 1-9.

Leyser, O. (2002). Molecular genetics of auxin signaling. Annu. Rev. Plant Biol. 53, 377-398.

Li, H., Zhou, S. Y., Zhao, W. S., Su, S. C., and Peng, Y. L. (2009). A novel wall-associated receptor-like protein kinase gene, OsWAK1, plays important roles in rice blast disease resistance. Plant Mol. Biol. 69, 337-346.

Lionetti, V., Cervone, F., and Bellincampi, D. (2012). Methyl esterification of pectin plays a role during plant-pathogen interactions and affects plant resistance to diseases. $J$. Plant Physiol. 169, 1623-1630.

Lionetti, V., Francocci, F., Ferrari, S. Volpi, C., Bellincampi, D., Galletti, R., et al. (2010). Engineering the cell wall by reducing de-methyl-esterified homogalacturonan improves saccharification of plant tissues for bioconversion. Proc. Natl. Acad. Sci. U.S.A. 107, 616-621.

Lionetti, V., Raiola, A., Camardella, L., Giovane, A., Obel, N., Pauly, M., et al. (2007). Overexpression of pectin methylesterase inhibitors in Arabidopsis restricts fungal infection by Botrytis cinerea. Plant Physiol. 143, 1871-1880.

Lotze, M. T., Zeh, H. J., Rubartelli, A., Sparvero, L. J., Amoscato, A. A., Washburn, N. R., et al. (2007). The grateful dead: damage-associated molecular pattern molecules and reduction/oxidation regulate immunity. Immunol. Rev. 220, 60-81.

Marfa, V., Gollin, D. J., Eberhard, S., Mohnen, D., Darvill, A., and Albersheim, P. (1991). Oligogalacturonides are able to induce flowers to form on tobacco explants. Plant J. 1, 217-225. Mauro, M. L., De Lorenzo, G., Costantino, P., and Bellincampi, D.
(2002). Oligogalacturonides inhibit the induction of late but not of early auxin-responsive genes in tabacco. Planta 215, 494-501.

McGurl, B., Pearce, G., OrozcoCardenas, M., and Ryan, C. A. (1992). Structure, expression, and antisense inhibition of the systemin precursor gene. Science 255, 1570-1573.

Moerschbacher, B. M., Mierau, M., Graeßner, B., Noll, U., and Mor, A. J. (1999). Small oligomers of galacturonic acid are endogenous suppressors of disease resistance reactions in wheat leaves. J. Exp. Bot. 50, 605-612. Moffat, C. S., Ingle, R. A., Wathugala, D. L., Saunders, N. J., Knight, H., and Knight, M. R. (2012). ERF5 and ERF6 play redundant roles as positive regulators of JA/Et-mediated defense against Botrytis cinerea in Arabidopsis. PLoS ONE 7:e35995. doi: 10.1371/journal.pone.0035995

Moloshok, T., Pearce, G., and Ryan, C. A. (1992). Oligouronide signaling of proteinase inhibitor genes in plants: structure-activity relationships of diand trigalacturonic acids and their derivatives. Arch. Biochem. Biophys. 294, 731-734.

Navarro, L., Dunoyer, P., Jay, F., Arnold, B., Dharmasiri, N., Estelle, M., et al. (2006). A plant miRNA contributes to antibacterial resistance by repressing auxin signaling. Science 312 , 436-439.

Nishimura, M. T., Stein, M., Hou, B. H., Vogel, J. P., Edwards, H., and Somerville, S. C. (2003). Loss of a callose synthase results in salicylic aciddependent disease resistance. Science 301, 969-972

Nothnagel, E. A., McNeil, M., Albersheim, P., and Dell, A. (1983). Host-pathogen interactions. XXII. A galacturonic acid oligosaccharide from plant cell walls elicits phytoalexins. Plant Physiol. 71, 916-926.

O’Donnell, P. J., Calvert, C., Atzorn, R., Wasternack, C., Leyser, H. M. O., and Bowles, D. J. (1996). Ethylene as a signal mediating the wound response of tomato plants. Science 274, 1914-1917.

Orozco-Cardenas, M., and Ryan, C. A. (1999). Hydrogen peroxide is generated systemically in plant leaves by wounding and systemin via the octadecanoid pathway. Proc. Natl. Acad. Sci. U.S.A. 96, 6553-6655.

Osorio, S., Castillejo, C., Quesada, M. A., Medina-Escobar, N., Brownsey, G. J., Suau, R., et al. (2008). Partial demethylation of oligogalacturonides by pectin methyl esterase 1 is required for eliciting defence responses in wild strawberry (Fragaria vesca). Plant J. 54, 43-55. 
Pelloux, J., Rusterucci, C., and Mellerowicz, E. J. (2007). New insights into pectin methylesterase structure and function. Trends Plant Sci. 12, 267-277.

Raiola, A., Lionetti, V., Elmaghraby, I., De Lorenzo, G., Cervone, F., and Bellincampi, D. (2010). "High methylesterification of pectin reduces the susceptibility of plants to fungal and bacterial pathogens," in Biology of Plant-Microbe Interactions, Vol. 7, eds H. Antoun, L. Brisson, M. Trepanier, T. Avis, and D. Prévost (Saint Paul: International Society for Molecular Plant-Microbe Interactions), 1-5.

Raiola, A., Lionetti, V., Elmaghraby, I., Immerzeel, P., Mellerowicz, E. J., Salvi, G., etal. (2011). Pectin methylesterase is induced in Arabidopsis upon infection and is necessary for a successful colonization by necrotrophic pathogens. Mol. Plant Microbe Interact. 24 432-440.

Randoux, B., Renard-Merlier, D., Mulard, G., Rossard, S., Duyme, F., Sanssene, J., et al. (2010). Distinct defenses induced in wheat against powdery mildew by acetylated and nonacetylated oligogalacturonides. Phytopathology 100 , 1352-1363.

Ranf, S., Eschen-Lippold, L., Pecher, P., Lee, J., and Scheel, D. (2011). Interplay between calcium signalling and early signalling elements during defence responses to microbe- or damage-associated molecular patterns. Plant J. 68, 100-113.

Rasul, S., Dubreuil-Maurizi, C., Lamotte, O., Koen, E., Poinssot, B., Alcaraz, G., et al. (2012). Nitric oxide production mediates oligogalacturonide-triggered immunity and resistance to Botrytis cinerea in Arabidopsis thaliana. Plant Cell Environ. 35, 1483-1499.

Reymond, P., and Farmer, E. E. (1998). Jasmonate and salicylate as global signals for defense gene expression. Curr. Opin. Plant Biol. 1, 404-411.

Reymond, P., Weber, H., Damond, M., and Farmer, E. E. (2000). Differential gene expression in response to mechanical wounding and insect feeding in Arabidopsis. Plant Cell 12, 707-720.

Rojo, E., Leon, J., and SanchezSerrano, J. J. (1999). Cross-talk between wound signalling pathways determines local versus systemic gene expression in Arabidopsis thaliana. Plant J. 20, 135-142.

Rojo, E., Solano, R., and SanchezSerrano, J. J. (2003). Interactions between signaling compounds involved in plant defense. J. Plant Growth Regul. 22, 82-98.

Ryan, C. A., and Jagendorf, A. (1995). Self defense by plants. Proc. Natl. Acad. Sci. U.S.A. 92, 4075.

Ryan, C. A., and Moura, D. S. (2002). Systemic wound signaling in plants: a new perception. Proc. Natl. Acad. Sci. U.S.A. 99, 6519-6520.

Savatin, D. V., Ferrari, S. Sicilia, F., and De Lorenzo, G. (2011). Oligogalacturonide-auxin antagonism does not require posttranscriptional gene silencing or stabilization of auxin response repressors in Arabidopsis. Plant Physiol. 157, 1163-1174.

Scheibner, K. A., Lutz, M. A., Boodoo, S. Fenton, M. J., Powell, J. D., and Horton, M. R. (2006). Hyaluronan fragments act as an endogenous danger signal by engaging TLR2. J. Immunol. 177, 1272-1281.

Simpson, S. D., Ashford, D. A., Harvey, D. J., and Bowles, D. J. (1998). Short chain oligogalacturonides induce ethylene production and expression of the gene encoding aminocyclopropane 1-carboxylic acid oxidase in tomato plants. Glycobiology 8, 579-583.

Spiro, M. D., Bowers, J. F., and Cosgrove, D. J. (2002). A comparison of oligogalacturonide- and auxin-induced extracellular alkalinization and growth responses in roots of intact cucumber seedlings. Plant Physiol. 130, 895-903.

Stennis, M. J., Chandra, S., Ryan, C. A., and Low, P. S. (1998). Systemin potentiates the oxidative burst in cultured tomato cells. Plant Physiol. 117, 1031-1036.

Sun, J. Q., Jiang, H. L., and Li, C. Y. (2011). Systemin/Jasmonatemediated systemic defense signaling in tomato. Mol. Plant 4, 607-615.

Taylor, K. R., Yamasaki, K., Radek, K. A., Di Nardo, A., Goodarzi, H., Golenbock, D., et al. (2007). Recognition of hyaluronan released in sterile injury involves a unique receptor complex dependent on Toll-like receptor 4, CD44, and MD-2. J. Biol. Chem. 282, 18265-18275.

Tor, M., Lotze, M. T., and Holton, N. (2009). Receptor-mediated signalling in plants: molecular patterns and programmes. J. Exp. Bot. 60, 3645-3654.

Ulmasov, T., Hagen, G., and Guilfoyle, T. J. (1997). ARF1, a transcription factor that binds to auxin response elements. Science 276, 1865 1868.

Verica, J. A., Chae, L., Tong, H. Y., Ingmire, P., and $\mathrm{He}, \mathrm{Z} . \mathrm{H}$. (2003). Tissue-specific and developmentally regulated expression of a cluster of tandemly arrayed cell wallassociated kinase-like kinase genes in Arabidopsis. Plant Physiol. 133, 17321746.

Wagner, T. A., and Kohorn, B. D. (2001). Wall-associated kinases are expressed throughout plant development and are required for cell expansion. Plant Cell 13, 303-318.

Wolf, S., Hematy, K., and Hofte, H. (2012). Growth control and cell wall signaling in plants. Annu. Rev. Plant Biol. 63, 381-407.

Wolf, S., Mouille, G., and Pelloux, J. (2009). Homogalacturonan methylesterification and plant development. Mol. Plant 2, 851-860.

Zhang, J., Shao, F., Li, Y., Cui, H., Chen, L., Li, H., et al. (2007). A Pseudomonas syringae effector inactivates MAPKs to suppress PAMP-induced immunity in plants. Cell Host Microbe 1, 175-185.

Zhang, S., Chen, C., Li, L., Meng, L., Singh, J., Jiang, N., et al. (2005)
Evolutionary expansion, gene structure, and expression of the rice wallassociated kinase gene family. Plant Physiol. 139, 1107-1124.

Zhou, N., Tootle, T. L., and Glazebrook, J. (1999). Arabidopsis PAD3, a gene required for camalexin biosynthesis, encodes a putative cytochrome P450 monooxygenase. Plant Cell 11, 2419-2428.

Zipfel, C., Kunze, G., Chinchilla, D., Caniard, A., Jones, J. D. G., Boller, T., etal. (2006). Perception of the bacterial PAMP EF-Tu by the receptor EFR restricts Agrobacteriummediated transformation. Cell 125, 749-760.

Zipfel, C., Robatzek, S., Navarro, L., Oakeley, E. J., Jones, J. D., Felix, G., et al. (2004). Bacterial disease resistance in Arabidopsis through flagellin perception. Nature 428, 764-767.

Conflict of Interest Statement: The authors declare that the research was conducted in the absence of any commercial or financial relationships that could be construed as a potential conflict of interest.

Received: 30 November 2012; paper pending published: 02 January 2013; accepted: 25 February 2013; published online: 13 March 2013.

Citation: Ferrari S, Savatin DV, Sicilia $F$, Gramegna $G$, Cervone $F$ and De Lorenzo G (2013) Oligogalacturonides: plant damage-associated molecular patterns and regulators of growth and development. Front. Plant Sci. 4:49. doi: 10.3389/fpls.2013.00049

This article was submitted to Frontiers in Plant Physiology, a specialty of Frontiers in Plant Science.

Copyright (c) 2013 Ferrari, Savatin, Sicilia, Gramegna, Cervone and De Lorenzo. This is an open-access article distributed under the terms of the Creative Commons Attribution License, which permits use, distribution and reproduction in other forums, provided the original authors and source are credited and subject to any copyright notices concerning any third-party graphics etc. 